\title{
Development of an Adjustable Bowen Ratio Instrumentation System
}

\author{
Kazuhiko YAGI ${ }^{1}$ and Haruhiko MURASE \\ Department of Regional Environmental Science, Osaka Prefecture University, 1-1 \\ Gakuen, Sakai, Osaka 599-8531, Japan \\ $\left({ }^{1} E-m a i l:\right.$ hqj $02670 @$ nifty.com)
}

\begin{abstract}
The proposed adjustable Bowen ratio instrumentation system consists of a BREB instrumentation system, an internal process to evaluate the calculated evapotranspiration rates, and a system controller that configures the instrumentation system for the acquisition of the most appropriate environmental parameters and hence accurate energy fluxes. There is a need to establish a process in which the reliability of calculated evapotranspiration rates is judged.

In order to develop a procedure to judge the reliability of evapotranspiration rates for the said Bowen ratio instrumentation system, the relationship between the location of the arms of sensors and the boundary layer in which the sensors must be located, was investigated. A modified Bowen ratio instrumentation system was used to measure two evapotranspiration (ET) rates, ETs and ETl, evaluated at two different heights : $50 \mathrm{~cm}$ and $90 \mathrm{~cm}$, respectively, at the same location. By comparing the two ET rates and processed data, three possible cases of the locations of the boundary layer relative to the arms were clarified. This clarification procedure could be used to appraise ET rates measured at relatively small fields where the fetch requirement might not always be met, and therefore could be employed for the adjustable Bowen ratio instrumentation system.
\end{abstract}

Keywords : Bowen ratio, boundary layer, evapotranspiration, sensor location, fetch requirement, adjustable instrumentation system

\section{Introduction}

Real-time or near real-time irrigation scheduling using the Bowen ratio energy balance(BREB) method demonstrated by $\mathrm{Yagi}^{1}{ }^{1}$, or using other parameters confirmed by Lascano et al. ${ }^{2)}$ is promising for water and energy conservation. The Bowen ratio method is to partition energy balance at the soil surface into latent heat and sensible heat fluxes. The energy balance can be expressed as

$$
R_{n}-G-E T-H=0
$$

where $\mathrm{Rn}:$ net radiation $\left(\mathrm{W} / \mathrm{m}^{2}\right)$

$\mathrm{G}$ : soil heat flux $\left(\mathrm{W} / \mathrm{m}^{2}\right)$

ET : latent heat flux $\left(\mathrm{W} / \mathrm{m}^{2}\right)$

Received 23 October 1998

Accepted 23 January 2001
$\mathrm{H}$ : sensible heat flux $\left(\mathrm{W} / \mathrm{m}^{2}\right)$

By introducing Bowen ratio, $\beta$, which is a ratio of sensible heat flux to latent heat flux, the above energy balance equation can be modified to

$$
E T=\frac{R_{n}-G}{1+\beta}
$$

The Bowen ratio can be determined by measuring vapor pressure and temperature gradients, and is expressed as follows.

$$
\beta=\gamma \frac{d T}{d e}
$$

where $\gamma:$ psychrometric constant for a given location

$\mathrm{dT}$ : temperature gradient

de : vapor pressure gradient

The BREB method requires measurements of air temperatures and vapor pressures, at two heights, 
separated by 1 meter in many cases, in addition to other parameters such as net radiation and soil heat $\mathrm{flux}^{3)}$. The proper application of the BREB method can be secured by considering and meeting a fetch requirement. A fetch, the distance from the upwind field edge to where the measuring system is located, needs to be more than 100 meters to secure the parameter acquisition within the boundary layer of the crop of interest. The BREB method is known to give accurate evapotranspiration rates ${ }^{4,5,6)}$, but its application has been limited to rather large fields to avoid influences from neighboring fields on the parameters to be measured.

However, the fetch requirement may not always be met when the BREB method is applied to relatively small fields. This is accompanied by uncertainty in measured air temperature and vapor pressure gradients; hence calculated evapotranspiration rates ${ }^{7}$. Yagi et $a l .^{8)}$ proposed a Bowen ratio instrumentation system which was equipped with functions to assess calculated evapotranspiration rates and control the sensor system so that the most representative parameters are sensed to obtain accurate evapotranspiration rates even in smaller fields. When the evapotranspiration rates are judged to be reliable, the database is updated and the parameter acquisition continues. On the other hand, when the rates are found unreliable or when the data are suspended from judgement, the system controller directs the sensor system so that the sensor arms can be configured to seek more appropriate arm settings referring to the database.

It is, therefore, of great importance to understand the relationship between relative location of the boundary layer to the location of sensors for air temperature and vapor pressure for the determination of energy fluxes. In order to develop an adjustable Bowen ratio instrumentation system, a procẻdure to clarify the relative location and to evaluate evapotranspiration rates needs to be established.

\section{Objectives}

This paper presents the following :

1. Clarification of relative locations of the boundary layer to the sensor's location using the modified Bowen ratio instrumentation system (Fig. 1), and

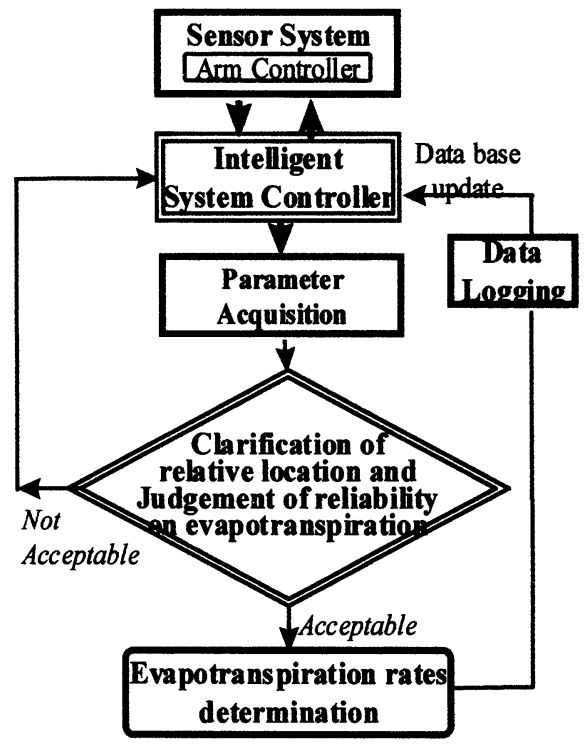

Fig. 1 Adjustable Bowen ratio instrumentation system

2. Establishment of a procedure to appraise the reliability of the calculated evapotranspiration rates

\section{Materials and Methods}

\section{Experimental field}

The experiment was conducted at a wheat field of Tsukuba International Centre, JICA in May 1998. The wheat was finally harvested in mid-June, 1998. The field plan including instrument location is shown in Fig. 2. Table 1 explains directions and distances to the upwind field edges of various lines drawn in Fig. 2. For example, line 1 shows the edge of the tree area at

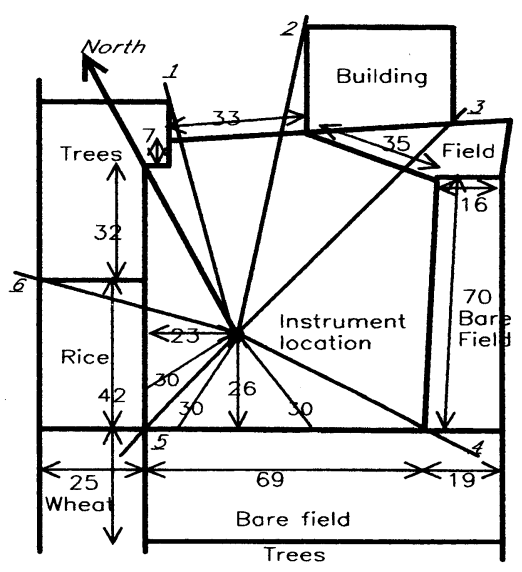

Fig. 2 Plan of the experimental field 
Table 1 Directions and distances of lines drawn in Fig. 1

\begin{tabular}{ccc}
\hline \hline $\begin{array}{c}\text { Line number } \\
\text { (italic) }\end{array}$ & Direction & Distance \\
\hline North & $0^{\circ}$ & $53 \mathrm{~m}$ \\
\hline 1 & $12^{\circ}$ & $57 \mathrm{~m}$ \\
\hline 2 & $37^{\circ}$ & $58 \mathrm{~m}$ \\
\hline 3 & $67^{\circ}$ & $63 \mathrm{~m}$ \\
\hline 4 & $145^{\circ}$ & $52 \mathrm{~m}$ \\
\hline 5 & $245^{\circ}$ & $34 \mathrm{~m}$ \\
\hline 6 & $313^{\circ}$ & $24 \mathrm{~m}$ \\
\hline
\end{tabular}

the upper-left corner of the field and the distance from the instrument location to the upwind field edge was 57 m. The largest fetch-height ratio was more than 100 at line 3 for $50 \mathrm{~cm}$ set, while the smallest was about 27 at line 6 for $90 \mathrm{~cm}$ set.

\section{Modified Bowen ratio instrumentation system}

A conventional Bowen ratio instrument system usually consists of two arms for the measurement of air temperature and vapor pressure gradients in addition to sensors for net radiation and soil heat flux. Another set of two arms was added to the conventional system so that two sets of air temperature and vapor pressure gradients were measured concurrently. Two arms evaluated one set of vapor pressure and temperature gradients, one arm was set at just above the crop canopy and the other $50 \mathrm{~cm}$ above the canopy. The second set of arms was set so that the gradients were evaluated between just above the crop canopy and $90 \mathrm{~cm}$ above the canopy. ETs and ETl denote evapotranspiration rates evaluated by the $50 \mathrm{~cm}$ set and $90 \mathrm{~cm}$ set; respectively. Table 2 shows compo- nents and details of parameters measured. The wheat at the field was about $80 \mathrm{~cm}$ in height. Yagi et al. ${ }^{9)}$ reported the developed modified Bowen ratio instrumentation system functioned properly and produced reliable evapotranspiration rates under ideal conditions, which were when the fetch-height ratio was satisfied without tall obstacles.

\section{Results and Discussion}

\section{Relative locations of arms to layer}

There are three possible cases for the relative locations of the arms to the boundary layer as shown in Fig. 3. Case(a) in Fig. 3 indicates when all the arms are below the boundary layer, case $(b)$ is when the highest arm is above the layer, and case (c) is when the two upper arms are above the layer. For example, in
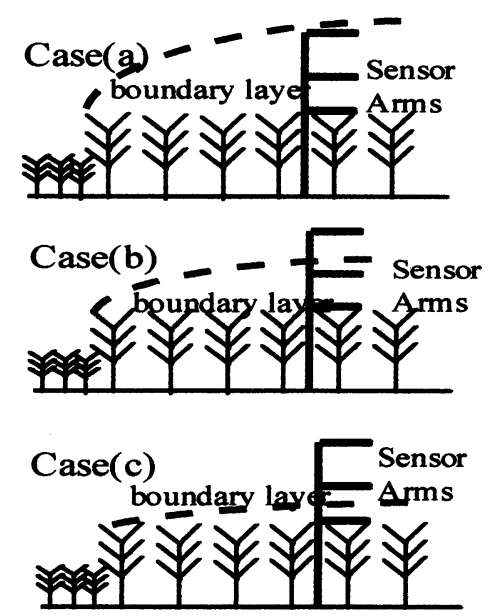

Fig. 3 Relative locations of boundary layer to sensor arms

Table 2 Data measurement and processing

\begin{tabular}{llllll}
\hline \hline & $\begin{array}{l}\text { Air } \\
\text { temperature } \\
\left({ }^{\circ} \mathrm{C}\right)\end{array}$ & $\begin{array}{c}\text { Vapor } \\
\text { pressure } \\
(\mathrm{kPa})\end{array}$ & $\begin{array}{c}\text { Net radiation } \\
\left(\mathrm{W} / \mathrm{m}^{2}\right)\end{array}$ & $\begin{array}{l}\text { Soil heat } \\
\text { flux } \\
\left(\mathrm{W} / \mathrm{m}^{2}\right)\end{array}$ & $\begin{array}{l}\text { Wind } \\
\text { speed } \\
(\mathrm{m} / \mathrm{s})\end{array}$ \\
\hline $\begin{array}{l}\text { Measuring } \\
\text { method }\end{array}$ & $\begin{array}{l}\text { Wire } \\
\text { Chromel- } \\
\text { constantan } \\
\text { thermocouple }\end{array}$ & $\begin{array}{l}\text { Cooled-mirror dew } \\
\text { point temperature } \\
\text { system }\end{array}$ & $\begin{array}{l}\text { Net } \\
\text { radiometer }\end{array}$ & $\begin{array}{l}\text { Soil heat } \\
\text { flux plate } \\
\text { and thermo- } \\
\text { couple }\end{array}$ & $\begin{array}{l}\text { Cup } \\
\text { anemo- } \\
\text { meter }\end{array}$ \\
\hline $\begin{array}{l}\text { Measuring } \\
\text { interval }\end{array}$ & Every second & $\begin{array}{l}\text { Every second for } \\
\text { last 80 seconds, } \\
\text { change height at } \\
\text { every 2 minutes }\end{array}$ & Every 10 seconds \\
\hline Processing & \multicolumn{1}{c}{ Average every 20 minute } \\
\hline
\end{tabular}


case(b) of Fig. 3, the evapotranspiration rates calculated by $90 \mathrm{~cm}$ set, ETl, may not be reliable, as measured air temperatures and vapor pressures were not the parameters of the crop of interest but of upwind field crops. Whereas ETs, evapotranspiration rates evaluated by $50 \mathrm{~cm}$ set, would be reliable.

\subsection{Clarification of case (a)}

$\mathrm{Rn}-\mathrm{G}$ value means the available energy for latent and sensible heat transfer at the soil surface. Fig. 4 shows ETs/ (Rn-G) values during daytime hours, from $9: 00$ to $16: 40$. It shows stable ETs/ $(R n-G)$ values for data when wind direction was between around 70 to 140 degrees. Ideal conditions for evapotranspiration determination, satisfying the fetch requirement without upwind obstacles, were when wind directions were between 12 and 37 degrees and between 67 and 145 degrees from Fig. 2 and Table 1. As shown in Fig. 4, ETs/(Rn-G)values were stable at these wind directions, and ETs values were reasonable and realistic. ETl values recorded only 5\% difference against ETs in the same range, which resulted ET-ratios, ETl/ETs, to be stable at close to unity. It was found that case (a) in Fig. 3, applied when the wind direction was between 12 and 37 and between 67 and 145 degrees, showed stable ET-ratios at close to unity and stable ETs/ (Rn-G) values.

\section{2 Clarification of case (c)}

For the clarification of case(c), data found to belong to case(a)were removed from all the data measured from $9: 00$ to $16: 40$. Fig. 5 shows the relationship between ETs/ $(\mathrm{Rn}-\mathrm{G})$ and wind direction for data excluding case(a) explained above. Significant fluctuations of ETs/ $(\mathrm{Rn}-\mathrm{G})$ at wind directions between around 220 and 320 degrees are evident. Table 3 reveals that only $12.5 \%$ of the data fell within

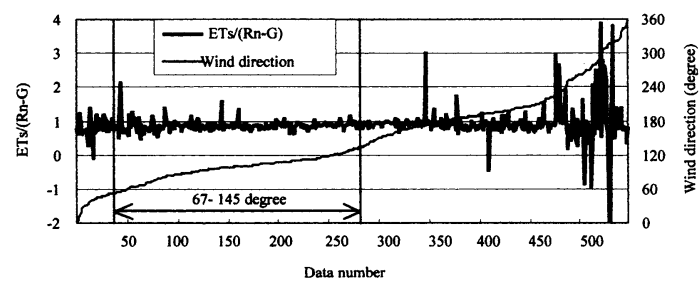

Fig. 4 Relationship between ETs/ $(\mathrm{Rn}-\mathrm{G})$ and wind direction using all data measured between $9: 00$ to $16: 40 \mathrm{hrs}$

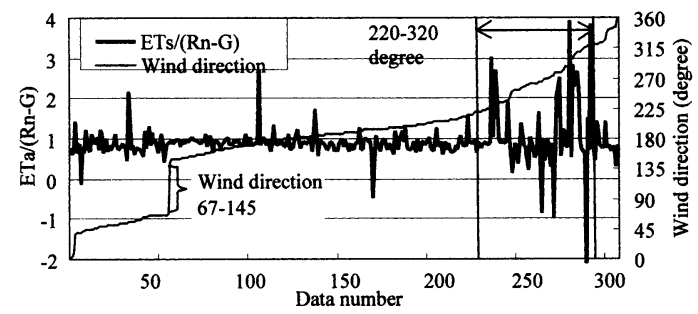

Fig. 5 Relationship between ETs/ $(R n-G)$ and wind direction using data except wind direction between 12 and 37 degrees and 67 and 145 degrees that were clarified to belong to case (a)

the average ETs/ $(\mathrm{Rn}-\mathrm{G}) \pm 0.1$ and $31.3 \%$ within the average ETs/ $(\mathrm{Rn}-\mathrm{G}) \pm 0.2$ for data when the wind direction was between 220 and 320 , which was very different from the other wind directions. The fluctuations implied that the $50 \mathrm{~cm}$ set did not sense parameters within the boundary layer of wheat, but sensed parameters affected by neighboring fields or upwind field crops. This conformed to case (c) in Fig. 3, and was signified by fluctuations of ETs/(Rn-G). Fig. 2 and Table 1 at this range revealed that fetch length was less than $30 \mathrm{~m}$ with discontinued upwind neighboring surfaces.

\section{3 Clarification of case $(b)$}

Fig. 6 shows ETl/ $(\mathrm{Rn}-\mathrm{G})$ values using the remaining data after excluding the data belonging to cases (a) and (c). The significance of case (b) would be stable and reliable ETs with variable and unreliable ETl. This would result in fluctuating $\mathrm{ETl} /(\mathrm{Rn}-\mathrm{G})$ as the sensors of the $90 \mathrm{~cm}$ set sensed parameters different from the $50 \mathrm{~cm}$ set. From Fig. 6, fluctuations of ETl/

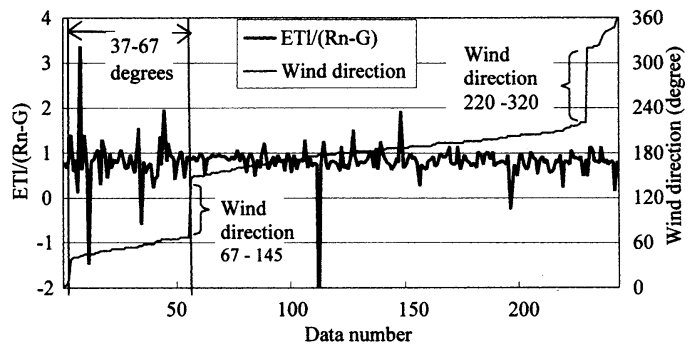

Fig. 6 Relationship between ETI/ $(\mathrm{Rn}-\mathrm{G})$ and wind direction using data except wind direction between 12 and 37 degrees, 67 and 145, and 220 and 320 degrees that were clarified to belong to cases (a) and (c) 
Table 3 Comparison of ETs/ $(R n-G)$ for clarification of case (c)

\begin{tabular}{|c|c|c|c|c|}
\hline & \multirow[b]{2}{*}{$\begin{array}{l}\text { Total } \\
\text { data }^{\text {a) }}\end{array}$} & \multicolumn{3}{|c|}{ Total Data except case (a) } \\
\hline & & $\mathrm{All}^{\mathrm{b})}$ & $\begin{array}{l}220<\text { Wind } \\
\text { direction }<320\end{array}$ & $\begin{array}{l}\text { Other wind } \\
\text { direction }\end{array}$ \\
\hline Number of data & 548 & 308 & 64 & 244 \\
\hline Average ETs/(Rn-G) & 0.902 & 0.923 & 1.048 & 0.890 \\
\hline $\begin{array}{l}\text { Number and percentage }{ }^{\dagger} \text { of data within } \\
\text { the average ETs/ }\left(\mathrm{Rn}^{-} \mathrm{G}\right) \pm 0.10\end{array}$ & $\begin{array}{l}288 \\
(52.6 \%)\end{array}$ & $\begin{array}{l}134 \\
(43.5 \%)\end{array}$ & $\begin{array}{c}8 \\
(12.5 \%)\end{array}$ & $\begin{array}{l}127 \\
(52.0 \%)\end{array}$ \\
\hline $\begin{array}{l}\text { Number and percentage } e^{\dagger} \text { of data within } \\
\text { the average ETs } /\left(\mathrm{Rn}^{-} \mathrm{G}\right) \pm 0.20\end{array}$ & $\begin{array}{l}427 \\
(77.9 \%)\end{array}$ & $\begin{array}{l}210 \\
(68.2 \%)\end{array}$ & $\begin{array}{l}20 \\
(31.3 \%)\end{array}$ & $\begin{array}{l}188 \\
(77.0 \%)\end{array}$ \\
\hline
\end{tabular}

a) : All measured daytime data from $9: 00$ to $16: 40 \mathrm{hr}$

b) : Data except when wind direction was between 12 and 37, and 67 and 145 degrees.

$\dagger$ : Percentage is shown in bracckets

Table 4 Comparison of ETI/(Rn-G) for clarification of case(b)

\begin{tabular}{|c|c|c|c|}
\hline & \multicolumn{3}{|c|}{ Data except cases $(\mathrm{a})$ and $(\mathrm{c})$} \\
\hline & $\mathrm{All}^{\mathrm{a})}$ & $\begin{array}{l}37<\text { Wind } \\
\text { direction }<67\end{array}$ & $\begin{array}{l}\text { Other wind } \\
\text { direction }\end{array}$ \\
\hline Number of data & 244 & 53 & 191 \\
\hline Average of $\mathrm{ETl} /(\mathrm{Rn}-\mathrm{G})$ & 0.835 & 0.821 & 0.832 \\
\hline Standard deviation of ETl/ $(\mathrm{Rn}-\mathrm{G})$ & 0.308 & 0.616 & 0.198 \\
\hline Number of data within the average $\mathrm{ETl} /(\mathrm{Rn}-\mathrm{G}) \pm 0.20$ & 174 & 27 & 147 \\
\hline Percentage of data within the average $\mathrm{ETl} /(\mathrm{Rn}-\mathrm{G}) \pm 0.20$ & $71.3 \%$ & $50.9 \%$ & $77.0 \%$ \\
\hline Average of ETs/(Rn-G) & 0.890 & 0.864 & 0.900 \\
\hline Standard deviation of ETs/ (Rn-G) & 0.268 & 0.310 & 0.255 \\
\hline
\end{tabular}

a): Data except cases (a) and (c), i. e. data except when wind direction was between 12 and 37,67 and

145 , and 220 and 320 degrees

$(\mathrm{Rn}-\mathrm{G})$ were observed when the wind direction was between 37 and 67 degrees. Table 3 shows similar average $\mathrm{ETl} /(\mathrm{Rn}-\mathrm{G})$ values for three categories but quite a large standard deviation of 0.616 for wind directions between 37 and 67 degrees and a rather low deviation of 0.198 for other wind directions. Table 4 also discloses less data falling within average ETl/ $(\mathrm{Rn}-\mathrm{G}) \pm 0.20$ for wind directions between 37 and 67 degrees than other wind directions, with similar averages and deviations of ETs/ (Rn-G) for all wind directions. Fig. 2 explains that the fetch length was more than $50 \mathrm{~m}$ but with obstacles in upwind direction when wind directions were between 37 and 67 degrees.

Some data were left undecided on their reliabilities as they did not show clear features as explained above in the three cases(a), (b) and (c). These data were not used to determine energy fluxes.

\section{Clarification procedure}

Clarification of relative locations of boundary layer to sensor arms using the evapotranspiration rates (ETs and ET1), ET-ratio, and surrounding environmental condition was explained above. The calcu-

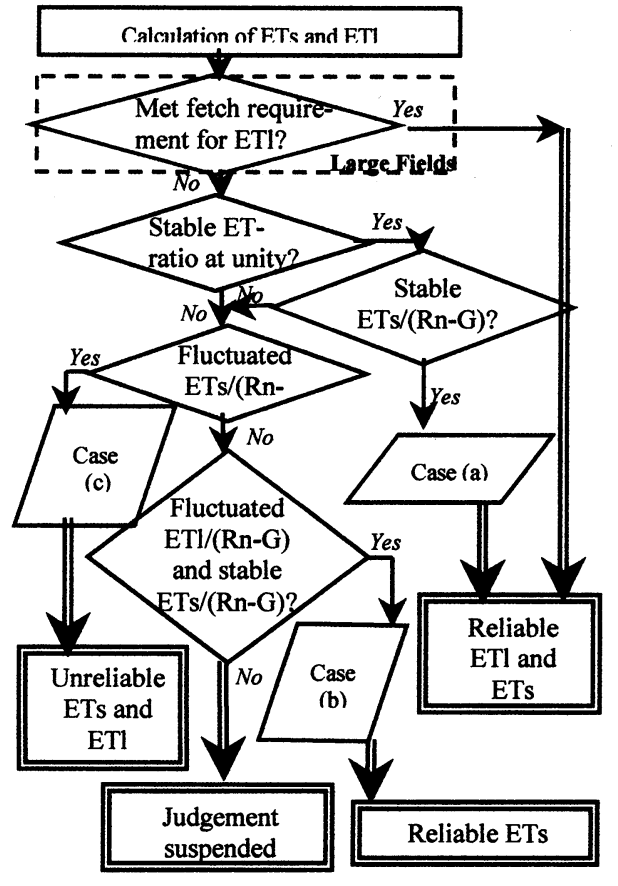

Fig. 7 Flow chart for clarification procedure of relative location and judging reliability of evapotranspiration rates 
lated evapotranspiration rates are evaluated on their reliability by finding the relative location of the boundary layer to the sensor arms. The process is shown in Fig. 7

The first process is added to indicate a conventional BREB method applied at relatively large fields where the fetch requirement was met. The lower parts were to clarify the relation between boundary layer and sensor arms, hence to judge the reliability of the calculated evapotranspiration rates.

\section{Conclusions}

Relative location of boundary layer to sensor arm was investigated using evapotranspiration rates, measured by the modified Bowen ratio instrumentation system, at relatively small fields in Tsukuba, where the fetch requirement of 100 was not always met. Three possible cases on the relative location of the boundary layer to the sensor arms were successfully clarified using two evapotranspiration rates(ETs and ET1), and processed data such as ET-ratio(=ETl/ ETs), ETs/ $(R n-G)$ and ETl/ $(R n-G)$ values. The clarification could be used to judge the reliability of calculated evapotranspiration rates, and also employed for the adjustable Bowen ratio instrumentation system so that sensors were configured to sense necessary parameters under unstructured and continuously changing natural conditions.

\section{Acknowledgement}

The authors would like to acknowledge the understanding and cooperation of many of the staff of
TBIC, JICA extended during the data acquisition and compilation of the paper.

\section{References}

1) Yagi, $K:$ Near real-time irrigation scheduling using the Bowen ratio technique, M. Sc. Thesis (unpublished), University of Arizona (1989)

2) Lascano, R. J., Baumhardt, R. L., Hicks, S. K., Evett, S. R., and Heilman, J. L. : Daily measurement and calculation of crop water use, Proc. of Int'l Conf. on Evapotranspiration and Irrigation Scheduling, ASAE, pp. 225-230 (1996)

3) Campbell Sci. Inc. : Bowen ratio instrumentation instruction manual(1995)

4) Prueger, J. H., Hatfield, J. L., Aase, J. K., and Pikul, J. L. Jr. : Bowen-ratio comparisons with lysimeter evapotranspiration, Agronomy J., 89 (5): 730-736 (1997)

5) Malek, T., and Bingham, G. T. : Comparison of the Bowen ratio-energy balance and the water balance methods for the measurement of evapotranspiration, J. of Hydrology, 146(1-4): 209-220 (1993)

6) Tanner, C. B. : Energy balance approach to evapotranspiration from crops, Soil Sci. Soc. Am. Proc. 24 : 1-9(1960)

7) Yagi, K., Murase, H. and Honami, N. : Automated evapotranspiration measurement using Bowen ratio technique for development of intelligent irrigation system, Proc. of ARBIP 98 (2): 169-174 (1995)

8) Yagi, K., Murase, H. and Honami, N. : Evapotranspiration measurement with Bowen ratio technique for the development of an intelligent irrigation system, App. Bio. Sci., 3 (1): 17 -23(1997)

9) Yagi, K., Murase, H. and Honami, N. : Development of a modified Bowen ratio instrumentation system, App. Bio. Sci., 4(1): 69-75(1998) 